\title{
Insulin degradation: radioimmunoassay for glutathione-insulin transhydrogenase and its application
}

\author{
P.T. Varandani and M. A. Nafz \\ Endocrinology Section, Fels Research Institute and Department of Biological Chemistry, School of Medicine and College of Science and \\ Engineerring, Wright State University, Dayton, Ohio, USA
}

\begin{abstract}
Summary. A double-antibody radioimmunoassay for the insulin-degrading enzyme, glutathione-insulin transhydrogenase (GIT), has been developed with the use of rabbit antiserum against human liver GIT and $\left[{ }^{125} \mathrm{I}\right]$-GIT. The method can determine as little as $32 \mathrm{fmol}$ of GIT, thus allowing measurements in needle tissue biopsy samples and in plasma, which have not been possible with previous enzymatic procedures. Relative competition in the radioimmunossay by unlabelled GITs purified from other sources are in agreement with homologies in GITs previously found using the enzymatic assay. No competition was observed with pork insulin, bovine ribonuclease, human albumin or human $\gamma$-globulin, indicating that the radioimmunoassay is highly specific for GIT. Similar competition curves were observed for native GIT; active, reduced GIT; or for the inactive, S-(ethylsuccinimido) derivative of GIT. The radioimmunoassay thus measures total (active + inactive) GIT and permits determinations in the pres-
\end{abstract}

ence of materials which react with the active site and render the enzymatic methods unusable. Radioimmunoassay of plasma and extracts of liver, muscle and adipose tissues from diabetic and non-diabetic subjects showed parallel competition curves with standard purified human GIT indicating that GITs of non-diabetic and diabetic persons are immunologically very similar or identical. Concentrations of GIT in plasma determined by radioimmunoassay were significantly higher in diabetic than those in non-diabetic subjects $(1620 \pm 80$ versus $1070 \pm 30 \mathrm{fmol} / 1, p<0.001$ ). Tissue GIT levels found by the radioimmunoassay as well as by the enzyme assay, both in non-diabetic and diabetic subjects, were highest in the liver, intermediate in the adipose tissue und lowest in the muscle.

Key words: Insulin degradation, glutathione-insulin transhydrogenase, radioimmunoassay, human tissues.
The processes of insulin inactivation and degradation are of extreme interest because excessive rates of inactivation and degradation of insulin could conceivably cause diabetes and/or could alter the hormone action in target tissues. However, the exact role of these processes, particularly in human diabetes, remains elusive.

Previous work from this and other laboratories has reported on the sequential pathway of insulin degradation [1-6]. According to this pathway, insulin is first split at the disulphide bonds by glutathione-insulin transhydrogenase (GIT) into A and B chains which are then hydrolyzed by two peptidases, neutral thiol peptidase and neutral metallo-peptidase, into low-molecular-weight fragments. Since separated A and B chains are devoid of hormonal activity, the action of GIT upon insulin results in the complete inactivation of hormonal activity. Several lines of evidence indicate that GIT, the first enzyme in the pathway, may be physiologically important [7]. Studies with animals have shown that the enzyme is ubiquitous [8]. Hepatic GIT is inducible by insulin
[9-11] and its activity is regulated by several factors including other hormones [12] and certain phospholipids [13]. In the liver, the enzyme primarily occurs in the microsomes in latent (depot) and non-latent (active) forms [14]; the two forms occur in different proportions under different physiological and pathophysiological conditions $[10,15-17]$. Studies with human subjects have shown that, while acute changes in plasma insulin levels provoked by glucose tolerance tests have no effect [18], diabetes and/or chronic insulin therapy result in increased GIT activity in circulating leucocytes [19]. Finally, chronic (studied in animal liver GIT [7, 9-11] or acute (studied in human leucocyte GIT [18] hyperglycaemia has been found to have no effect on GIT activity.

To permit studies in human diabetes, we report here on the development of a radioimmunoassay (RIA) for human GIT. Human tissues (liver, muscle and adipose) from non-diabetic and diabetic subjects obtained at autopsy by the National Diabetes Research Interchange 
were utilized for the identification of GIT by immunodiffusion tests and for comparison of the RIA with the enzyme assay procedure. This study illustrates the use of the RIA procedure for measuring plasma GIT levels of non-diabetic and diabetic subjects. Portions of these studies have been published previously [20,21].

\section{Materials and methods}

\section{Materials}

Goat anti-rabbit IgG, human albumin and human $\gamma$-globulin were purchased from Miles, Elkhart, Indiana, normal rabbit serum from Grand Island Biological Company, Grand Island, New York, ribonuclease from Worthington, Freehold, New Jersey; bovine serum albumin (BSA), reduced glutathione (GSH) and N-ethylmaleimide from Sigma, St. Louis, Missouri. Carrier-free ${ }^{125} \mathrm{I}$-iodine was purchased from New England Nuclear Corporation, Boston, Massachusetts. Amorphous pork insulin was a gift of Dr. R. Chance, Eli Lilly, Indianapolis, Indiana. Purified preparations of GIT from human liver, rat liver, beef liver, beef heart and beef pancreas were obtained as described previously $[22,23]$. The purified human liver GIT used in standardizing the assay was prepared from a fresh liver obtained from a non-diabetic subject following accidental death [22]. The purified human enzyme was a homogeneous material by starch block electrophoresis and by Sephadex G-100 chromatography $[22,23]$ and had a sp. act. of $530 \mathrm{U} / \mathrm{nmol}$. Antiserum to human liver GIT was prepared in rabbits as previously described [23].

Different forms of purified human liver GIT were prepared as described previously [24]. The active, reduced form ( $530 \mathrm{units} / \mathrm{nmol})$ was prepared by treatment of the enzyme with $1 \mathrm{mmol} / 1 \mathrm{GSH}$. The inactive, S-(ethylsuccinimido) derivative (with no enzymatic activity) was prepared by treatment of the enzyme, first with $1 \mathrm{mmol} / 1 \mathrm{GSH}$, followed by treatment with $\mathrm{N}$-ethylmaleimide $(10 \mathrm{mmol} / \mathrm{l})$. As a reagent control, another sample of the enzyme was treated with $\mathrm{N}$ ethylmaleimide $(10 \mathrm{mmol} / \mathrm{l}$ without a prior reaction with $\mathrm{GSH}$; in this case, the enzyme is unaffected and remains enzymatically active after activation with GSH [24].

\section{Human tissues}

All tissues (liver, muscle, adipose) from non-diabetic and diabetic subjects were obtained at autopsy by National Diabetes Research Interchange personnel, quick frozen at $-80^{\circ} \mathrm{C}$ and sent to our laboratory on dry ice. Non-diabetic subjects were aged 49-81 years, and diabetic subjects $33-86$ years. The interval between death and autopsy varied from 8 to $15 \mathrm{~h}$.

\section{Preparation of tissue extracts}

Each tissue $(2 \mathrm{~g})$ was homogenized in $8 \mathrm{ml}$ of $0.25 \mathrm{~mol} / 1$ sucrose/ $50 \mathrm{mmol} / 1 \mathrm{~K}$-phosphate $(\mathrm{pH} 7.5)$ with a homogenizer (Polytron PT10 , Brinkmann Instruments, Westbury, New York) at $80 \%$ of maximum speed for $60 \mathrm{~s}$. The homogenates were centrifuged at $5000 \mathrm{~g}$ for $10 \mathrm{~min}$ and the resulting supernatants were then centrifuged at $10000 \mathrm{~g}$ for $20 \mathrm{~min}$. The final supernatants were assayed for protein and GIT content, both by RIA and the enzymatic assay.

\section{Immunodiffusion}

Double-immunodiffusion plates were composed of a solution containing $1 \%$ agar in $\mathrm{NaCl}(0.154 \mathrm{~mol} / 1)$, K-phosphate $(0.02 \mathrm{~mol} / 1)$, glycine $(0.5 \mathrm{~mol} / \mathrm{l}), \mathrm{pH} 7.5$ [23]. Tissue extracts were prepared as described above, and also with the homogenizing buffer supplemented with $0.5 \%$ (final concentration) Triton X-100. The tissue extracts were concentrated by lyophilization and reconstituted in the above immunodiffusion buffer for the immunodiffusion tests.

\section{GIT radioimmunoassay}

Purified human liver GIT was radioiodinated with the use of Iodobeads (Pierce Chemicals, Rockford, Illinois) [25]. ${ }^{125}$ I-GIT was purified by gel filtration on a Sephadex G-100 column at a 2-3 week interval. The separation of antibody-bound ${ }^{125}$ I-GIT from free ${ }^{125}$ I-GIT was achieved by using a double antibody procedure [26]. All solutions and dilutions were made with RIA buffer (K-phosphate $(0.1 \mathrm{~mol} / \mathrm{l})$, EDTA $(5 \mathrm{mmol} / \mathrm{l}), \mathrm{NaCl}(0.154 \mathrm{~mol} / \mathrm{l}), \mathrm{pH} 7.5$, containing $0.3 \%$ bovine serum albumin). The procedure was as follows: standard human liver GIT (32-320 fmol), or an appropriately diluted tissue extract or plasma sample $(25-100 \mu \mathrm{l})$, was mixed with ${ }^{125} \mathrm{I}$-GIT $(\sim 16 \mathrm{fmol})$ and $25 \mu l$ of 1:5000 diluted GIT antiserum (i.e., 1:50000 final dilution) in a total volume of $0.25 \mathrm{ml}$. Typical dilutions of tissue extracts were 1:1000 for liver, and 1:25 for muscle and adipose tissues. The samples were incubated for $5 \mathrm{~min}$ at $37^{\circ} \mathrm{C}, 60 \mathrm{~min}$ at $25^{\circ} \mathrm{C}$ and $20-24 \mathrm{~h}$ at $4{ }^{\circ} \mathrm{C}$. The next day, $0.1 \mathrm{ml}$ of EDTA ( $\mathrm{pH} 7.5$, yielding a final concentration of $15 \mathrm{mmol} / \mathrm{l}), 0.1 \mathrm{ml}$ of $1: 100$ diluted normal rabbit serum and $0.1 \mathrm{ml}$ of goat anti-rabbit $\operatorname{IgG}$ were added. After an additional incubation at $4^{\circ} \mathrm{C}$ for $20-24 \mathrm{~h}, 1.0 \mathrm{ml}$ of RIA buffer was added to each tube and the tubes were centrifuged at $2200 \mathrm{~g}$ at $4^{\circ} \mathrm{C}$ for $15 \mathrm{~min}$. The supernatants were aspirated and the pellets were counted in an auto-gamma counter (Packard, Downers Grove, Illinois). The ${ }^{125}$ I-GIT bound by the antibody was calculated as the percentage of the radioactivity added. In the presence of tracer alone, $35 \%$ of the ${ }^{125}$ I-GIT was bound by the antibody. Control tubes to determine non-specific binding were run with normal rabbit serum substituted for the antibody. All values have been corrected for non-specific binding, which was usually $2-4 \%$ of the total radioactivity.

\section{GIT enzymatic assay}

This method will hereafter be referred to as the enzyme assay. Enzymatic activity of GIT in tissue extracts was assayed by measuring the conversion of ${ }^{125} \mathrm{I}$-insulin to a form soluble in a $5 \%$ trichloroacetic acid (TCA) solution, utilizing assay conditions that have been found to limit the degradation of insulin by liver homogenates to only that effected by GIT [10]. Briefly, each tissue extract (3-4 levels in duplicate) was incubated at $37^{\circ} \mathrm{C}$ in $0.9 \mathrm{ml}$ of $\mathrm{K}$-phosphate buffer $(0.1 \mathrm{~mol} / \mathrm{l})$ (pH 7.5) containing EDTA $(5 \mathrm{mmol} / \mathrm{l})$ and $1 \mu \mathrm{mol}$ reduced GSH. After $5 \mathrm{~min}$, the reaction was started by adding $0.1 \mathrm{ml}$ of a solution containing $1 \mathrm{nmol}$ of insulin, a tracer amount of ${ }^{125} \mathrm{I}$-insulin and $3 \mathrm{mg}$ of BSA. After an additional $5 \mathrm{~min}$ incubation the reaction was terminated by the addition of $10 \% \mathrm{TCA}(1.0 \mathrm{ml})$. The precipitates were collected and washed by centrifugation as described previous [10]. One unit of GIT activity is defined as the net degradation of $1 \%$ (i.e., $10 \mathrm{pmol}$ ) of the insulin (total radioactivity) present in the assay tube. All activities were corrected for non-enzymatic degradation which was determined from matched control tubes containing no tissue protein.

\section{Blood plasma samples}

All of the 15 non-diabetic subjects were healthy staff members of the University (aged 22-54 years, within 10\% of ideal body mass). They had no known history of metabolic abnormalities. All of the 31 diabetic subjects were outpatients (aged 19-69 years). Ten had Type 1 (insulin-dependent) diabetes, between 90 and $130 \%$ of ideal body mass, and the remaining 21 had Type 2 (non-insulin-dependent) diabetes weight ranging from 105 to $190 \%$ of ideal body mass. The duration of diabetes ranged from 1 to 35 years for Type 1 and from 1 to 34 years for Type 2 patients. All the Type 1 group were on insulin therapy. Of the 21 Type 2 subjects, nine were on insulin therapy, two were on chlorpropamide (Pfizer, New York, NY) and the remaining 10 were on diet alone. Informed, written consent was obtained from all subjects. 

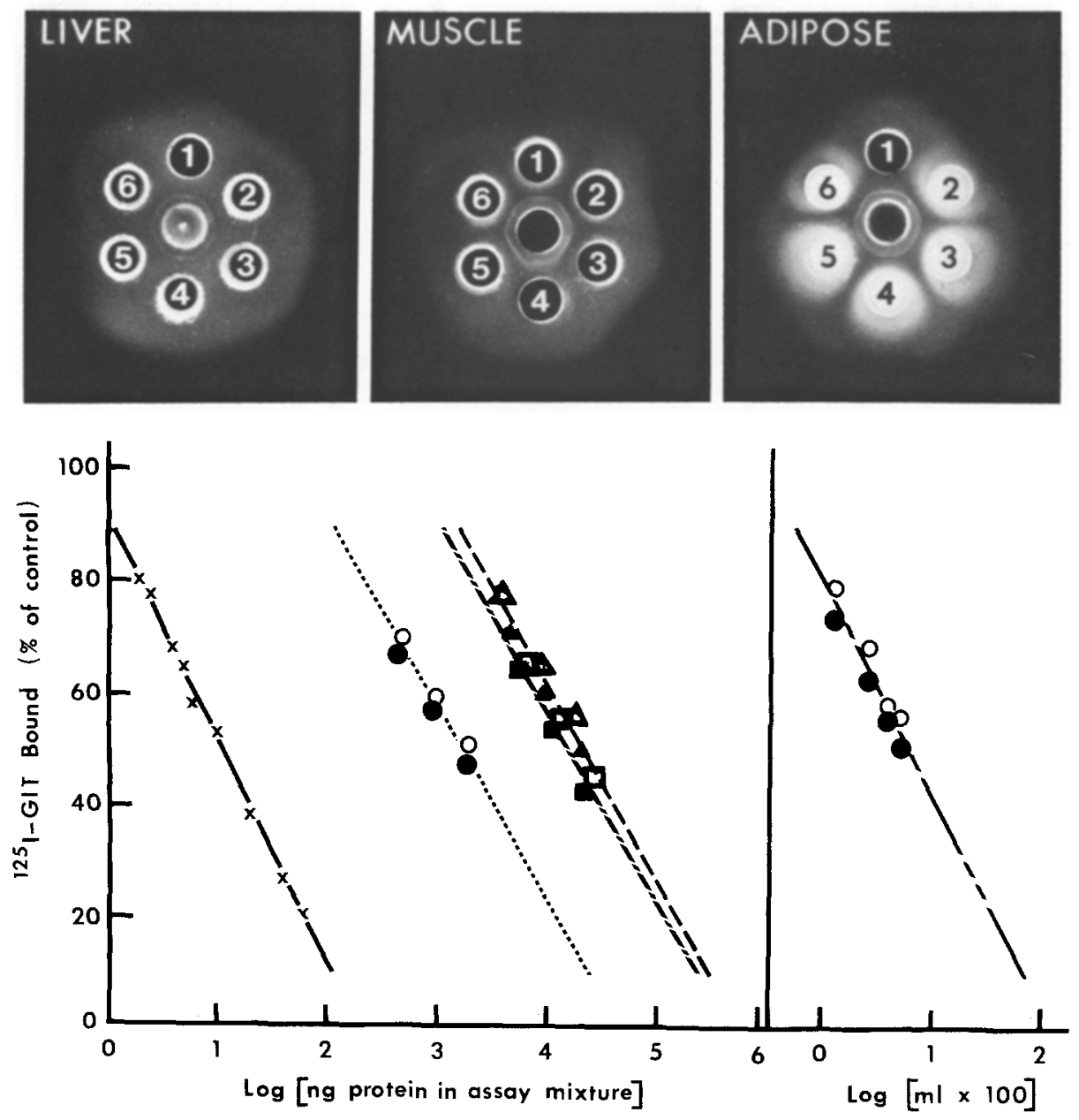

Fig. 1. Immunodiffusion analysis (Ouchterlony) of extracts of liver, muscle and adipose tissues of non-diabetic and diabetic subjects. Rabbit antiserum to human liver GIT was present in each centre well. The peripheral wells contained purified human liver GIT [1], tissue extracts from three different diabetic $(2,3,4)$ and from two different non-diabetic $(5,6)$ subjects. Diffusion was carried out at $4^{\circ} \mathrm{C}$ for $1-7$ days

\section{Laboratory methods}

Blood samples were collected in heparinized tubes and centrifuged at $1000 \mathrm{~g}$ for $10 \mathrm{~min}$ at $5^{\circ} \mathrm{C}$. The plasma was removed and stored frozen. Before assay, plasma samples were centrifuged to remove fibrous material which had formed during freezing. Assay of fresh or frozen and centrifuged plasma from the same subject gave the same values within the error of the assay. All samples were assayed at four dilutions in duplicate. Since preliminary assays showed no effect of overnight fasting on plasma GIT concentrations, blood samples were withdrawn in the post-prandial state.

Protein concentrations were determined by the method of Lowry et al. [27], using BSA as standard.

\section{Statistical analysis}

All results are presented as mean \pm SEM. The significance of differences between means was determined by the Student's t-test.

\section{Results}

\section{Immunodiffusion}

The presence of GIT-like immunoreactive material was demonstrated by the immunodiffusion technique in all the extracts of three tissues (liver, muscle, and adipose) from two non-diabetic and three diabetic subjects (Fig.1). Each extract showed a single precipitin band which was continuous with the precipitin line of purified GIT and also with those of the other tissue extracts from diabetic and non-diabetic subjects. The buffer used for the preparation of muscle and adipose tissue extracts contained $0.5 \%$ Triton X-100. When the extracting buffer did not contain Triton, a precipitin band was found with each tissue, although the intensity of these precipitin bands appeared weaker than those with extracts obtained with buffer containing Triton. The qualitative increase in the intensity of the precipitin band with Triton was greater with muscle than with the other tissues. Since addition of Triton to Polytroned tissue extracts had no significant effect on the level of GIT measured by the RIA (data not shown), it is possible that the Triton addition facilitates the diffusion of the enzyme resulting in the increaseed intensity of the precipitin bands. A single precipitin band with each extract of these tissues clearly indicates that the antibody to GIT is specific for GIT.

\section{Radioimmunoassay}

A typical standard curve of the RIA, which used a 1: 50000 dilution of antiserum, is shown in Figure 2. This standard curve has a range of 32-320 fmol. The most routinely used enzyme assay, which utilizes ${ }^{125}$ I-insulin 


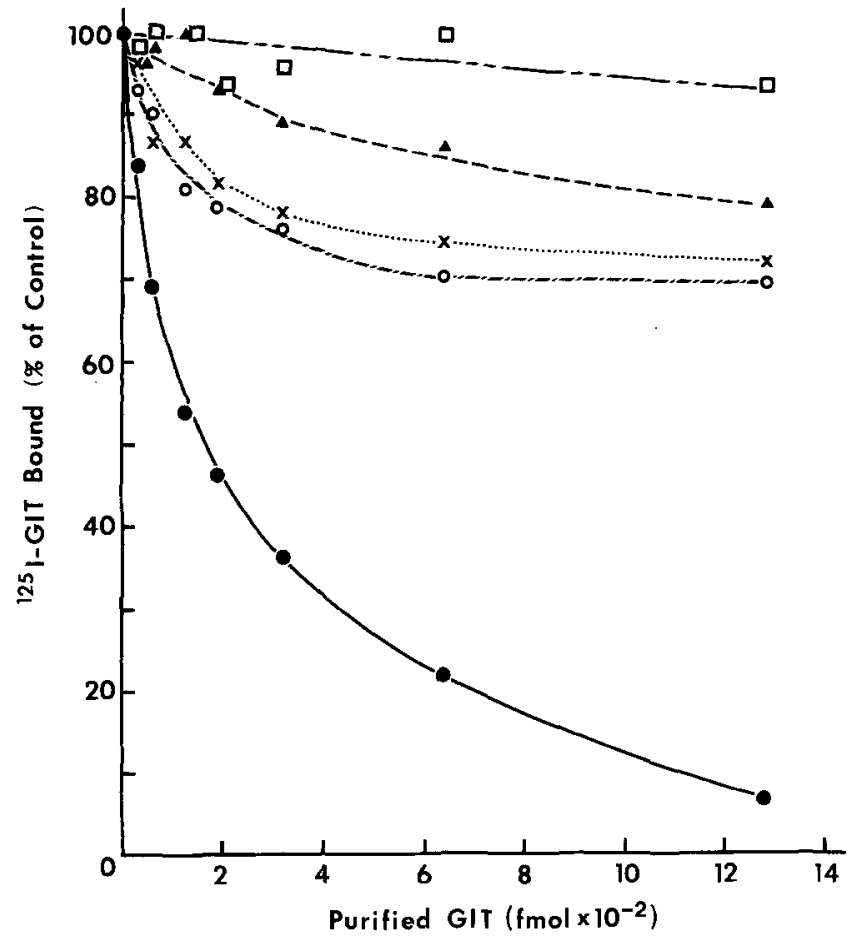

Fig.3. Specifictiy of the RIA for human liver GIT. Native unlabelled GIT isolated from bovine liver $(\mathrm{O}-\mathrm{O})$, rat liver $(x-\cdots)$, bovine pancreas $(\boldsymbol{\Delta} \Delta)$ and bovine heart $(\square-\square)$ were tested for their ability to compete with human liver $\left[{ }^{125} \mathrm{I}\right]-\mathrm{GIT}(\boldsymbol{- O})$ for binding by the GIT antibody using the two-antibody radioimmunoassay procedure

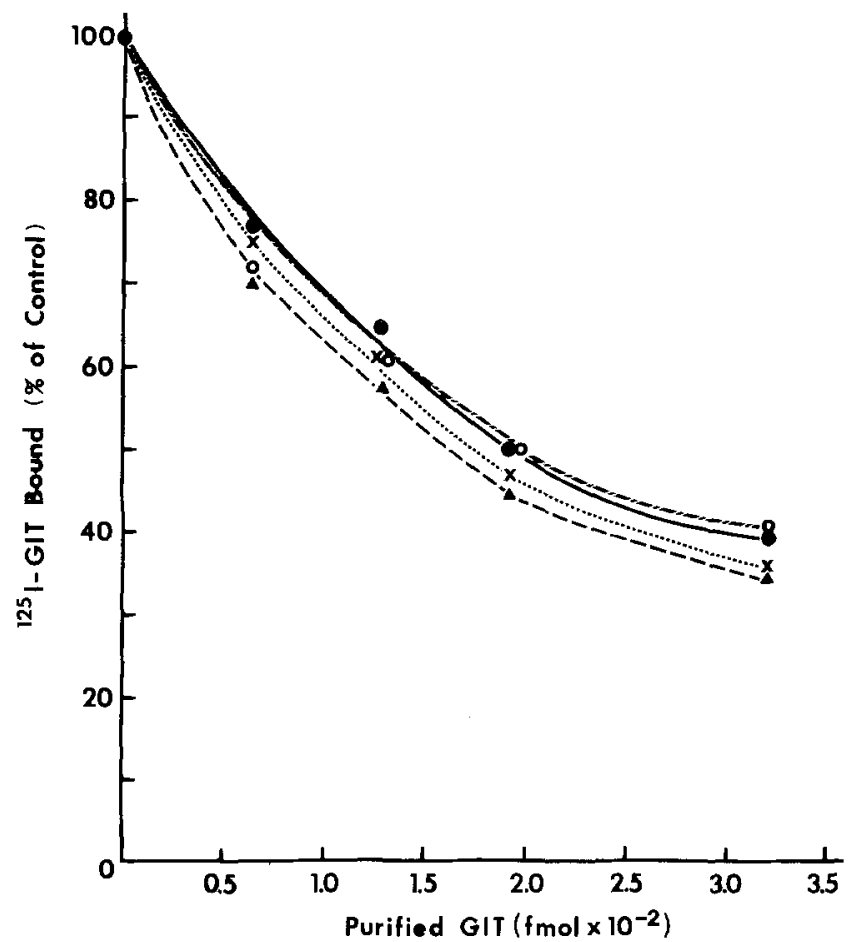

Fig.4. Comparison of the immunoreactivity of active and inactive forms of the purified human liver GIT. Unlabelled native GIT $(-0)$; active, reduced GIT $(\mathrm{O}-\mathrm{O})$; inactive, S(ethylsuccinimido) derivative of GIT $(\mathbf{\Delta}--\mathbf{\Delta})$; and, as a reagent control (see Methods section), active N-ethylmaleimide-treated GIT $\left(x_{---.} \times\right)$ were tested for their ability to compete with [ $\left.{ }^{125} \mathrm{I}\right]-$ GIT for binding to GIT antibody using the double-antibody radioimmunoassay procedure

Table 1. Tissue and plasma GIT concentrations as determined by enzyme assay and by radioimmunoassay

\begin{tabular}{|c|c|c|c|c|c|c|}
\hline Sample & \multicolumn{3}{|c|}{ Non-diabetic subjects } & \multicolumn{3}{|c|}{ Diabetic subjects } \\
\hline Adipose & 8 & $7.6 \pm 0.8$ & $22.4 \pm 4.6(15)$ & 14 & $6.1 \pm 0.7$ & $24.3 \pm 3.5(16)$ \\
\hline Muscle & 8 & $3.1 \pm 0.5$ & $14.1 \pm 1.6(10)$ & 12 & $2.6 \pm 0.8 \quad(13)$ & $15.7 \pm 2.2(10)$ \\
\hline
\end{tabular}

Results are expressed as mean $\pm \mathrm{SEM}$; values in parentheses are relative to liver; ${ }^{\text {a }}$ fmol $\times 10^{3} / \mathrm{ml}$ for plasma; ${ }^{b} p<0.001$ for non-diabetic versus diabetic subjects

as the substrate and TCA precipitation, requires pmol quantities of the purified enzyme [28]. Thus, the RIA has 1000 times greater sensitivity than the enzyme assay. The intra- and interassay coefficients of variation for the RIA, as determined by repetitive, replicate assay of a human plasma pool, were $5.5 \%$ and $5.8 \%$, respectively.

The RIA also appeared to be highly specific, since none of the other proteins tested (pork insulin, bovine ribonuclease, human albumin and human gamma globulin), even at concentrations 10000 -fold more than human GIT, competed for the binding of $\left[{ }^{125} \mathrm{I}\right]$-human GIT to the antibody (data not shown). It is of interest, however, that unlabelled purified GIT isolated from other sources competed much less than unlabelled human liver GIT for binding of $\left.{ }^{125} \mathrm{I}\right]$-human GIT to the antibody (Fig.3). Relative competitions at $640 \mathrm{fmol}$ of unlabelled GIT were: human liver GIT (100), beef liver GIT (38), rat liver GIT (31), beef pancreas GIT (16) and beef heart GIT (0). The order of competition in the RIA was the same as the order of cross-reactivity observed previously in the antigen-antibody titrations using an enzymatic assay procedure $[23,29]$. The RIA did not discriminate between active and inactive forms of human GIT (Fig. 4), since similar competition curves were observed for native GIT; active, reduced GIT; or for an inactive, S-(ethylsuccinimido) derivative of GIT. Thus, the RIA measured total (active + inactive) GIT. 
Also shown in Figure 2 are the dilution curves from extracts of autopsy tissues and plasma from non-diabetic and diabetic subjects. Each curve is parallel to that for standard purified human GIT, indicating that the GIT present in both non-diabetic and diabetic subjects is immunologically indistinguishable. GIT added in vitro to plasma was quantitatively recovered using the radioimmunoassay procedure (data not shown).

\section{Quantitation of tissue and plasma GIT}

GIT levels in tissues from non-diabetic and diabetic subjects were quantitated by RIA and by the enzyme assay (Table 1). Both assays showed that the GIT level was highest in liver, intermediate in adipose tissue and lowest in muscle, both in non-diabetic and diabetic subjects. The plasma GIT level by the RIA was markedly higher in diabetic than in non-diabetic subjects $(p<0.001)$. There was no difference in the GIT concentration in the plasma of either Type 1 or Type 2 diabetic subjects; values therefore are presented together. Although the differences between non-diabetic and diabetic subjects were statistically significant for plasma $(p<0.001)$, there were no significant difference, in GIT levels of non-diabetic or diabetic subjects for any of the tissues studied either by enzyme assay or by RIA. This lack of statistical significance may be due to the large scatter in values, reasons for which are not clear. It may be related to the use of autopsy tissues, variable intervals between death and the removal of tissues at autopsy, and the uncontrollable variables in the tissue donors (age, duration of diabetes, dose of insulin, etc.).

\section{Discussion}

We have developed a radioimmunoassay for the measurement of human GIT which has sensitivity, specificity and precision. The assay is specific for human GIT since it cross-reacts only slightly with the GIT from beef and rat and since other commonly occurring plasma proteins, such as albumin or $\gamma$-globulin, had no effect. The assay measured as little as $32 \mathrm{fmol}$ of GIT which is three orders of magnitude more sensitive (i.e., 1000fold) than previously available enzymatic assays.

Human tissue extracts and blood plasma samples, both from diabetic and non-diabetic subjects, upon dilution showed curves parallel to standard purified human liver GIT, indicating that a protein immunologically indistinguishable from GIT occurs in the various human tissues and in plasma. Previous studies have shown the presence of GIT in human kidney [30], liver [22] and circulating leucocytes [18, 19], and erythrocytes [31]. Demonstration of GIT both by immunological and enzymological methods in three tissues (liver, muscle and adipose) in the current studies clearly indicates that, as in other animals [8], GIT is widely distributed in human tissues.

Previous enzymatic assay procedures have failed to detect an insulin-degrading enzyme in plasma, apparently because the concentration of the enzyme in plasma (average of $1070 \mathrm{fmol} / \mathrm{l}$ ) is far below the detection capability of the enzyme assays. Furthermore, since RIA does not distinguish between the enzymatically inactive and active forms of GIT, it is possible that GIT in the plasma occurs in an inactive form or as an inactive complex with other inhibiting proteins, and therefore would not be detectable by enzymatic activity procedures.

The occurrence of GIT in plasma raises a question about the origin of plasma GIT that is difficult to answer since GIT is ubiquitous (8, this study). While the human liver GIT antibody used was highly specific for human liver GIT, it cross-reacted with GIT from other organs within the same species [23, 29]. Thus, plasma GIT could have its source in tissues or, alternatively, it is possible that plasma GIT may simply arise from the turnover of blood cells, such as leucocytes and erythrocytes, which have been reported to contain the enzyme $[18,19,31]$. A major conclusion of the present study is that a protein immunologically similar to human liver GIT does indeed occur in human plasma. Studies using randomly selected subjects show that this GIT-like protein occurs at a significantly higher concentration in the plasma of diabetic subjects than in plasma of non-diabetic subjects. The finding of an elevated level of plasma GIT in diabetic subjects is consistent with previous studies reporting elevated levels both of leucocyte GIT activity in diabetic patients [19] and of plasma insulin A chain [32-34], which is a product of GIT-catalyzed insulin degradation. These findings would support the possible role of this enzyme in the aetiology of diabetes mellitus. Considering the low concentrations of GIT in plasma relative to other body tissues, it is unlikely that plasma GIT per se plays a quantitatively significant role in the pathogenesis of diabetes. It is possible, however, that plasma GIT may reflect the measure of glutathione-dependent insulin-degrading activity in the human system.

The availability of the radioimmunoassay for GIT should provide a valuable tool for studies in which the measurement of fmol amounts of this enzyme is required, such as needle biopsies, especially under situations where the enzyme may occur either in an inactive form or as a complex with an inhibitor. In fact, insulin resistance, or diminished effectiveness of subcutaneously administered insulin in certain diabetic patients, has recently been attributed to increased hormone degradation at several different locations including adipose tissue, muscle, injection site, serum and more central tissue [35]. The GIT radioimmunoassay procedure described here should directly help to delineate the role of GIT-mediated insulin degradation in such clinical situations. 
Acknowledgements. This work was supported, in part, by USPHS Research Grant AM-24057. Human tissues were supplied by National Diabetes Research Interchange.

\section{References}

1. Varandani PT, Shroyer LA, Nafz MA (1972) Sequential degradation of insulin by rat liver homogenates. Proc Natl Acad Sci USA 69: 1681-1684

2. Varandani PT (1973) Insulin degradation. IV. Sequential degradation of insulin by rat kidney, heart and skeletal muscle homogenates. Biochim Biophys Acta 295: 630-636

3. Varandani PT (1973) Insulin degradation. VII. Sequential degradation of insulin by rat liver homogenates at physiologic concentrations of insulin and in the absence of exogenous glutathione. Biochim Biophys Acta 320: 249-257

4. Varandani PT, Nafz MA (1976) Insulin degradation. XVI. Evidence for the sequential degradative pathway in isolated liver cells. Diabetes 25: 173-179

5. Kohnert KD, Jahr H, Schmidt S, Hahn HJ, Zuhlke H (1976) Demonstration of insulin degradation by thiol-protein disulfide oxidoreductase (glutathione-insulin transhydrogenase) and proteinases of pancreatic islets. Biochim Biophys Acta 422: 254-259

6. Izzo JL, Roncone AM, Helton DL, Izzo MJ (1979) Subcellular distribution of intraportally injected ${ }^{125} \mathrm{I}$-labeled insulin in rat liver. Arch Biochem Biophys 198: 97-109

7. Varandani PT (1977) The role of glutathione-insulin transhydrogenase in insulin degradation. In: Bajaj IS (ed) Diabetes. Proceedings of the 9th Congress of the International Diabetes Federation, New Delhi, India, 1976. Excerpta Medica, Amsterdam, pp 213-223

8. Chandler ML, Varandani PT (1964) Insulin degradation. II. The widespread distribution of glutathione-insulin transhydrogenase in the tissues of the rat. Biochim Biophys Acta 286: 136-145

9. Varandani PT (1974) Insulin degradation. VI. Feedback control by insulin of liver glutathione-insulin transhydrogenase in rat. Diabetes $23: 117-125$

10. Varandani PT, Nafz MA (1976) Insulin degradation. XVIII. On the regulation of glutathione-insulin transhydrogenase in the hyperglycemic obese (ob/ob) mouse. Biochim Biophys Acta 451: 382-392

11. Thomas JH (1973) The effect of insulin deficiency on glutathioneinsulin transhydrogenase activity of rat liver. Biochem Soc Trans 1: 1179-1182

12. Varandani PT, Nafz MA, Chandler ML (1975) Interaction of insulin analogs, glucagon, growth hormone, vasopressin, oxytocin, and scrambled forms of ribonuclease and lysozyme with glutathione-insulin transhydrogenase (thiol: protein-disulfide oxidoreductase): dependence upon conformation. Biochemistry 14: 2115-2120

13. Varandani PT, Nafz MA (1976) Interaction of glutathione-insulin transhydrogenase (disulfide interchange enzyme) with phospholipids. Biochim Biophys Acta 438: 358-369

14. Varandani PT (1973) Insulin degradation. V. Unmasking of glutathione-insulin transhydrogenase in rat liver microsomal membrane. Biochim Biophys Acta 304: 642-659

15. Thomas JH, Varandani PT (1979) Insulin degradation. XXV. Glutathione-insulin transhydrogenase activity of rat liver and kidney during the development of streptozotocin-diabetes. Biochim Biophys Acta $567: 88-95$

16. Hern EP, Varandani PT (1983) Topology of glutathione-insulin transhydrogenase in rat liver microsomes. Biochim Biophys Acta 732: $170-178$

17. Hern EP, Varandani PT (1983) Nonlatent and latent hepatic glutathione-insulin transhydrogenase activity during perinatal development and liver regeneration in rats and in rat placenta. Biochem Biophys Res Commun 116:909-915
18. Chandler ML, Varandani PT (1974) Insulin degradation. IX. On the presence of glutathione-insulin transhydrogenase in human leukocytes. Diabetes 23: 232-239

19. Theiss WC, Rupp GM, Varandani PT (1984) Insulin-degrading activity in mononuclear and polymorphonuclear circulating leukocytes of nondiabetic and diabetic subjects. J Clin Endocrinol Metab 59:344-349

20. Nafz MA, Varandani PT (1981) Development and application of radioimmunoassay of human glutathione-insulin transhydrogenase. Diabetes 30: 50A (Abstract)

21. Varandani PT, Nafz MA (1983) Development and application of a radioimmunoassay of the human insulin-degrading enzyme, glutathione-insulin transhydrogenase. In: Torgesson L, Riordan C, Pitcher O (eds) Proceedings of the 1st National Conference on the Utilization of Human Tissue: a new resource for diabetes research. National Diabetes Research Interchange, Philadelphia, pp $150-153$

22. Tomizawa HH, Varandani PT (1965) Glutathione-insulin transhydrogenase of human liver. J Biol Chem 240: 3191-3194

23. Varandani PT, Nafz MA (1970) Comparative studies of ultracentrifugal and immunological properties of glutathione-insulin transhydrogenases from beef pancreas, beef liver, human liver, and human kidney. Int $J$ Biochem 1: 313-321

24. Varandani PT, Plumley H (1968) Mechanism of action of glutathione-insulin transhydrogenase. Presence of a functional sulfhydryl group for activity. Biochim Biophys Acta 151: 273-275

25. Markwell MK (1982) A new solid state reagent to iodinate proteins. I. Conditions for the efficient labeling of antiserum. Anal Biochem 125: 427-432

26. Morgan CR, Sorenson RL, Lazarow A (1964) Further studies on an inhibitor of the two antibody immunoassay system. Diabetes 13: $579-584$

27. Lowry OH, Rosebrough NJ, Farr AL, Randle RJ (1951) Protein measurement with the folin phenol reagent. J Biol Chem 193: $265-275$

28. Chandler ML, Varandani PT (1975) Insulin degradation. XV. Use of different assay methods for the study of mechanism of action of glutathione-insulin transhydrogenase. Biochim Biophys Acta 397: $307-317$

29. Varandani PT (1972) Insulin degradation. I. Purification and properties of glutathione-insulin transhydrogenase of rat liver. Biochim Biophys Acta 286: 126-135

30. Varandani PT, Nafz MA (1969) Glutathione-insulin transhydrogenase of human kidneys. Diabetes 18: 176-178

31. Brodal BP (1971) Evidence of enzymatic degradation of insulin in blood in vitro. Eur J Biochem 18: 201-206

32. Varandani PT (1968) Plasma concentrations of A and B chains of insulin in nondiabetic, diabetic and high risk potential diabetic subjects. Diabetes 17:547-556

33. Varandani PT (1970) Urinary excretion of insulin A chain by normal and diabetic subjects. Diabetes 19:98-101

34. Meek JC, Doffing KM, Bolinger RE (1968) Radioimmunoassay of insulin A and B chains in normal and diabetic human plasma. Diabetes 17:61-66

35. Maberly GF, Wait GA, Kilpatrick JA, Loten EG, Gain KR, Stewart RDH, Eastman CJ (1982) Evidence for insulin degradation by muscle and fat tissue in an insulin resistant diabetic patient. Diabetologia 23:333-336

Received: 15 August 1984

and in revised form: 29 April 1985

\section{Dr. P.T. Varandani}

Endocrinology Section

Wright State University

Dayton, Ohio 45435

USA 